\title{
The development of attachment theory: introduction and orientation
}

\author{
Muqing Liu
}

\author{
College of Labor and Human Resource, Renmin University of China, Beijing 100872, China \\ muqing.liu@ruc.edu.cn
}

Keywords: attachment, parenting, intergenerational transmission

\begin{abstract}
It has been nearly 70 years since attachment theory was first promoted by Bowlby, a British developmental psychologist and a psychoanalyst. After that, attachment theory has become the foundation of child development and parent-child relation research field. With the trend of using interdisciplinary research methods, traditional research on attachment theory has been largely expanded. This article summarized the development history and academic finding of attachment, then predicted the future orientation of attachment theory.
\end{abstract}

\section{The emergence and development of attachment theory}

\subsection{John Bowlby}

John Bowlby has been considered as the "founding father" of attachment theory. In the theory, he described how infants seek proximity from caregivers to maintain their survival based on evolutionary biological function during the very first month after birth. It includes the ways of feeding, nurturing and keeping the infants safe from harm (Holmes, 1993). His work was based on Lorenze's work on imprinting and ethological term of "behavior system", Bowlby postulated the word of "attachment behavior system" as a motivational system, independent from other systems nevertheless may interact with them. Bowlby developed attachment theory from the observation on children's reaction to breaking bonds from their primary care givers (primarily mother).

Besides exploring the evolutionary biological foundation of infants' attachment, Bowlby also promoted a hypothesis that individual differences in attachment function are connected with their "internal working models" towards themselves and others. This model determines whether individuals actively seek solutions during distressing events, withdraw and minimize the experiences, or amplify emotional responses (Main, 2000).

In his theory, "ease of emotional communication" is believed to be the heart of the development and maintenance of patterns of attachment, since it may come to promote security. "the principal function of emotion is one of communication - namely, the communication, both to the self and to others, of the current motivational state of the individual, "Thus what is happening in those early years is that the pattern of communication that a child adopts towards his mother comes to match the pattern of communication that she has been adopting towards him”' (Bowlby, 1991).

Bowlby views attachment theory as a "conceptual framework", in which new exploring new avenues of research and extension of theory was supported.

\subsection{Mary Ainsworth}

Based on attachment theory from John Bowlby, American psychologists Mary Ainsworth explored and deepened the research of infant-caregiver relationships. Her outstanding contribution includes The Strange Situation Procedure (SSP) and the division of qualitative nature of attachment (Ainsworth, Blehar, Waters \& Wall, 1978).

The SSP was designed to use the cues of unfamiliarity and separation to elicit potential anxiety regarding the availability of the familiar caregiver. As such, the procedure aimed to mobilize the infant's expectations about what happens when anxiety about the availability of the attachment figure has occurred in the past, and allowed a viewer to interpret these expectations from observed behavior.

Based on observation towards infants, Ainsworth classified infants into three different types 
according to their response towards separation and reunion with their caregivers. Ainsworth discovered that a majority of infants could use their caregivers as a "safe base" from which to explore, protested at their departure, but sought the caregiver upon their return. Such kind of infants were classified as "secure". Some infants showed little visible distress on separation or reunion with their caregiver, which was proved to be a mask of distress by later study on the heart rate of avoidant infants (Sroufe \&Waters, 1977). This type of infants' behavior was termed “Avoidant”. A third pattern was termed "Ambivalent/ Resistant", infants belong to such pattern showed distress even before separation and were extremely difficult to comfort after their caregivers return, even showed distrust on caregivers' availability when they were present.

Ainsworth and her colleagues observed 26 middle-class mother-infant dyads from Baltimore throughout the first year of life, more than 70 hours of observation were spent in each home. Each mother and infant came to the laboratory for assessment in the strange situation at the time of the infant's first birthday. She found that the congenital attachment system which believed to be driven by human evolutionary biology, was indeed to be malleable. The maternal quality of caregivers was the key to shape the individual differences on attachment patterns.

Ainsworth summarized that it is the quality of nonverbal communication that determined infants' security and how they perceive themselves. She and her colleagues assessed a great variety of dimensions of maternal behaviors at home, from which they found four rating scales (sensitivity, acceptance, cooperation and accessibility) were strongly related to attachment security. Central issue in attachment research concerns how security and patterns of attachment develop and change across time. Behaviorally-based concept of "sensitive responsiveness' has been shown to promote security in infancy: reflect the caregiver's ability to read emotional signals accurately and respond appropriately (Ainsworth et al., 1978).

What also needs to be concentrate on is that through her research, Ainsworth also studied how people communicate instead of what they communicate-since language convert what people really indicates in infant- caregiver communication. She focused on the process and way of communication instead of the content. Therefore, her longitudinal study revealed two important correlations:

Firstly, 12-month-old infants' attachment behaviors with their caregivers under The Strange Situation are correlated with their internal working structure when they are reassessed at 5 years old; Secondly, attachment patterns are found to be intergenerational, infants' behavior under The Strange Situation were correlated with caregivers' psychological states in attachment.

These two findings illustrated that infants' nonverbal behavior patterns can predict their representation patterns, which not only explained Bowlby's “internal working model”, but also lead later research to investigate the intergenerational transmission of attachment patterns.

\subsection{Mary Main}

Twenty years after Ainsworth work, her student Mary Main added a new type of attachment behavior pattern into Ainsworth's classification: disorganized/disoriented”. Disorganized/disoriented behaviors suggest either a conflict between simultaneous dispositions to physically approach and to flee the caregiver-or seeming disorientation to the environment. Infant behaviors coded as disorganized/disoriented include overt displays of fear of the caregiver; contradictory behaviors or affects occurring simultaneously or sequentially; stereotypic, asymmetric, misdirected, or jerky movement; or freezing and apparent dissociation.

Mary Main's another outstanding attribution of creating AAI (Adult attachment Interview) enabled "seeing" the internal world of children's and parents'. A series of questions were designed for the parents including recalling and thinking their relationships with their parents, and how they felt among lost, refusal and departure. In her longitudinal studies, The Strange Situations were used to assess infant-caregiver relationships instead of infants' characteristic. Infants would be assessed attachment with caregivers among their infant, toddler and early childhood. At the same time, caregivers would be assessed by AAI to be evaluated their "psychological states in attachment", which were believed to be independent from any social relationships. Her longitudinal studies 
enable one to see how early Strange Situation classifications to mother and to father relate to the AAI classification in adolescence or adulthood (Grossmann, Grossmann, \& Waters, 2005).

\subsection{Single factor decision theory of infants' attachment patterns}

Ever since the attachment theory has emerged, researchers have been pursuing the answer of some questions: how to understand the internal mechanism of attachment theory? Which factors are associated with infants' attachment patterns? Or which factors can decide the pattern of attachment? What prevention and intervention can be taken to format secure attachment? Since attachment is like a bond between infants and caregivers, the most frequently discussed factors by early researchers are from perspective on infants or mother.

\subsection{Maternal quality}

Traditional attachment researchers emphasized maternal quality effects, regarding them as the most crucial element in infant development and child psychopathology. According to Ainworth's Baltimore observation, researchers evaluated maternal quality by four rating scales: sensitivity, acceptance, cooperation, and accessibility. They were found to be strongly related to attachment security (Ainsworth et al., 1978, p. 152). Mothers of "secure" infants got the highest score among those four scales. Mothers of "avoidant" infants were found to be refused and lack sensibility, they tended to be negative and impatient with their children. Mothers of" Ambivalent/ Resistant" infants tend to scale low on accessibility and cooperation, they seemed to be willing to interact with their children however misunderstand infants' demands.

Many authors also found that sensitivity is a crucial antecedent of attachment security (Bretherton, 1985; Main, 1990; Sroufe, 1988). Isabella stated that attachment theory and research regards maternal sensitivity as an all-important characteristic of interaction which consistently related to attachment security (Isabella, 1993). Some studies were designed according to the basic features and conceptualizations of Ainsworth's Baltimore Study in order to test its accuracy( e.g., Belsky, Rovine, \& Taylor, 1984; Grossmann, Spangler, Suess, \& Unzner, 1985; Isabella, 1993), and they have yielded result that are close to Ainsworth original result( Belsky,Rovine\& Taylor,1984). However, according to De Wolff and Van Ijzendoorn's meta analysis research on 66 infants and their mothers, they found that maternal sensitivity can only explain $24-32 \%$ of infants' behavior under The Strange Situation. Thus, De wolff and Ven Ijzendoorn pointed out that maternal sensitivity is "an important but not the single influence factor" during the formation of infants' attachment (De wolff \& Ven Ijzendoorn, 1997).

\subsection{Infant temperature}

Considering infant temperament in the formation of attachment patterns, there used to be two competing views. Attachment researchers like Ainsworth believed that infants attachment behaviors are the function of dual social interaction, which was influenced mainly by maternal quality instead of infant temperament. On the contrary, some researchers promoted that infant temperament is the determinant factor of attachment patterns. They promoted that the differentiation in The Strange Observation represented infant temperament differentiation instead of attachment pattern differentiation (Kagan, J\& Snidman, N, 1991). In Calkins and Fox's research on the relations among infant temperament, attachment, and behavioral inhibition, they found that infants classified as resistant scored high on behavioral inhibition, infants classified as avoidant scored high on uninhibited behavior, and infants classified as secure scored none extreme on neither inhibited nor uninhibited behavior(D,Calkins \& N.A. Fox,1992). Researches on newborns have significantly improved that infant temperament played an important role on attachment formation and development, since newborns have the lowest social influence and their behaviors are mainly decided by natural temperament.

Though infant temperament was found to be influencing, it was not decisive. Despite newborn's differentiation on natural temperament, there still exist secure infants and insecure infants at close level of inhabitation and anxiety. Besides, if attachment quality is mainly decided by infant temperament, children are expected to formulate same attachment pattern towards both father and 
mother. However according to Fox's meta-analysis, though there exists highly consistency on attachment towards mother and father, the sub-classification (secure, avoidant, ambivalent $\backslash$ resistant) varies individually (N.A. Fox\&N.L. Kimmerly\&W.D. Schafer, 1991).

\subsection{Intergenerational transmission of attachment}

At the very beginning, the Adult Attachment Interview (AAI) was developed to explore to predict the quality of the infant-parent attachment relationship, as observed in the Ainsworth Strange Situation, and to predict parents' responsiveness to their infants' attachment signals. The classification under The Strange Situation can predict consequence of AAI, and latterly proved also to be predictable reversely. A meta-analysis conducted by van IJzendorn (1995) showed that the percentage of correspondence between parents' AAI results and infants' attachment pattern could be as high as 75\%, even though the AAI was implemented before parents actually had a baby. A recent longitudinal research showed links between first-time mothers' AAIs (provided during pregnancy) and their children's AAIs (provided at age 16 years). A study carried on 57 parents with childhood histories of abuse and neglect (CA\& $N$ ) and their children, aimed to evaluate the intergenerational transmission of attachment in abused and neglected mothers. This research showed that mothers with unresolved trauma experiences and low CR-f(reflective functioning regarding traumatic experiences, refers to parents' capacity to reflect upon their child's mental states and link them to their own and their child's behavior after traumatic experiences) ( Fonagy, Gergely, Jurist, \& Target, 2002) have a significant prediction of infants' disorganized attachment (Allen, 2013; Allen \& Fonagy, 2006; Fonagy \& Luyten, 2009; Luyten, Fonagy, Lowyck, \& Vermote, 2012).

\section{Multi-factors decision theory of infants' attachment pattern}

\subsection{Intergenerational transmission gap of attachment}

Some researches cast doubts on the gap of intergenerational transmission of attachment, finding that there are some samples showing irrelevance of intergenerational transmission of attachment. Despite van IJzendoorn found strong association between the SSP and AAI with a large effect size the association between maternal attachment security status and maternal sensitive responsiveness was found less robust, van IJzendoorn thus coined the term the "transmission gap," referring to that aspect of the attachment transmission process from parent to offspring which cannot be fully explained by maternal sensitivity.

To explain such findings, some researchers promoted that caregiver's attachment representations as an aspect of the shared environment were unclearly definite (Barbaro, Boutwell, Barnes, \& Shackelford, 2016). They urged that nonshared environmental influences (aspects of the environment that work to make individuals less similar to one another) should be distinguished from shared environment influence and behavior genetic should be valued in intergenerational attachment similarity and differentiation. Traditional methodology of The Strange Situation and AAIs are assessment of shared environment, and they cannot be expected to be significant through life span as well as remain attachment stability.

Some recent findings verified such promotion. Evidence of attachment stability from infancy to adulthood is found to be relatively weak (e.g., Groh et al., 2014; but see Fraley, 2002, for meta-analysis of published studies only). New research also demonstrates that there is only a small correlation between individuals' attachment to a parent (such as their mother) and their attachment to a romantic partner when assessed in adulthood (Fraley, Hudson, Heffernan, \&Segal, 2015).

Thus, hypothesis of attachment plasticity has been promoted, assuming that intergenerational transmission of attachment may be verified influenced by several factors.

\subsection{An interdisciplinary perspective of attachment}

Some researchers combine human ecology studies with attachment theory to consider the dynamic interplay among social, psychological and biological factors. Under further investigation among attachment factors, researchers began to combine environmental factors and individual characters 
together. Some researchers promoted that parent feeding decides whether the attachment pattern is secure or insecure, and infant temperature decides the specific pattern of insecure attachment. Some experiments also promoted that children with certain temperaments may be at risk for experiencing negative parent-child interactions, thus are more likely to be influenced by external factors and experiences like low maternal quality, which supported a new explanation of dynamic influence of environmental factors and individual characters.

Thus, human ecology perspective offered a new angle to comprehend human attachment theory: child-parent relation is multi-influenced by the ecological background, in which contains not only biological basis but also social, cultural or even historical contexts. The attachment theory should be considered as a dynamic system consisted of multiple factors in which factors are interacting and influencing each other.

According to Belsky's general model of determination of parenting (Belsky, 1984), personal psychological resources in parental functioning, characteristic of the child and contextual sources of stress and support are the three domains of parenting determinants. Parenting style is a multiply determinate process, how they parent their children was determinate by these three domains. They singled or combined influence parenting process directly or indirectly, thus affecting child-parent interaction. Besides their direct and indirect effects on parenting, the three domains are also interplaying and supplementing each other. For example, in families with high marital quality, mothers' attachment situation has no obvious correlation with infants' attachment security, however in families with low marital quality, mothers who belong to secure attachment are more liked to rear secure child than insecure mothers.

Based on Belsky's general model of parenting, new influence factors like parent ego-resiliency, education, sponsor support and parents' attachment security has been proved to be prominent and independent explanation, which has correlation with child attachment quality (e.g. Hedwig, Van Bakel, Riksen-Walraven, 2000).

\section{Biological perspective of attachment}

\subsection{Genetics}

When researchers looked at the answer to attachment from macroscopic behavior to microscopic molecular biology, genetics has been an essential part .The dual interplay of gene-environment has been long discussed for many years. However, the discovery of behavioral genetics and epigenetics may add some new prospect into it.

Evidence from last 20 years shows that social environment would mitigate the effects of gene expression in adaptive behavior and pathological behavior (Reiss \& Leve, 2007). And research of traumatic environment also showed that individual reaction verified in traumatic environment, from which resilience (resistance towards negative psychosocial influence) was promoted (Luthar et al., 2000). For this reason, internal psychological situation may not only be the result of gene-environment dual interplay but also the mediator.

As a newly founded subject, epigenetics has been more and more specially regarded in intergenerational transmission of attachment investigation. Epigenetics is the study of stable heritable changes in gene function that do not involve changes in the DNA sequence. The existence of intergenerational transmission of epigenetic modification also proved possibility of intergenerational transmission of insecure attachment and child psychopathology if parents have traumatic experiences in their childhood. According to Hosak's research in 2007, huge amount of factors including genetic fragile stimulated by environment are considered to support development of attachment behavior (Hosak, 2007).

\subsection{Neurobiological perspective}

With the development of neurology and neurobiology, neurobiological measures have been taken to investigate the biological and neurological foundation of attachment theory. By testing heart rate variability, blood pressure to test autonomic nervous system, testing neurotransmitters like cortisol, 
brain-derived neurotrophic factor, N-methyl-D-aspartate influence on infant right brain and prefrontal cortex development, testing neurotransmitters like oxytocin and 5-hydroxytryptamine impact on parenting style (e.g.Schore,2001;Robert,William,Robert,Jonathan \& David,2006; Wang, Bartolome, Schanberg, 1996). Such findings also opened a new opportunity to understand attachment security and expand ecological model for child-parent attachment development. Since the researchers tend to put security attachment in a more dynamic system, it is generally believed security attachment has an indispensable role in infants' development process. Attachment has been considered as the first interpersonal emotional bonding in everyone's life.

How did the interpersonal emotional neurobiological bonding happen? Interdisciplinary researchers found that it militated through myelinated ventral vagus and unmyelinated dorsal vagus, in order to build the consistency between maternal psycho-body reaction and infant autonomic nerves system activation level. Under such explanation, attachment security refers to synchronous reflective functioning between infants and caregivers. Thus, secure attachment experience stimulates neural factor levels with significant meaning to build social connection and brain development like neuropeptide (oxytocin), neuro-regulation (catecholamine) and neuroactive steroid (hydrocortisone) (Schore, 1994, 2005; Wismer Fries et al., 2005), and for a long term to promote development of hypothalamic- pituitary- adrenal( HPA).

Traumatic experience in childhood history may arouse different neurobiological reaction, after activating right brain, it whether overstimulate sympathetic nervous system to increase corticotrophin releasing factor, adrenaline, dopamine and pitressin to cause terror and fear( Kyetnansky et al., 1990), or to enter state of “dissociation”, individual become depressed and avoidant under circumstances of hopeless and helpless due to activation of parasympathetic nervous system, and at last become nonchalant. In long term, maltreatment including abuse and neglect has negative effect on attachment security and brain development, especially on right brain function on managing pressure and negative emotion (Sullivan\& Dufresne, 2006).

All these researches from different perspective would provide chances to explain the mystery of attachment. Moreover, it also has high applicable value on child psychopathology and development disorder prevention and intervention, as well as improve parent couple function and social context meanwhile.

\section{References}

[1] Allen, J.G. (2013). Mentalizing in the development and treatment of attachment trauma. London: Karnac Books.

[2] Allen, J.G., \& Fonagy, P. (2006). Handbook of mentalization-based treatment. Chichester, England: Wiley.

[3] Bowlby, J. (1969). Attachment and loss: Vol. 1. Loss. New York, NY: Basic Books.

[4] Bowlby, J. (1982). Attachment and loss: Vol. 2. Separation. New York, NY: Basic Books.

[5] Bowlby, J. (1944) Fourty-four juvenile thieves: their characters and home-life (II). International Journal of Psycho-Analysis, 25, 107-128.

[6] Ainsworth, M. D. S., Blehar, M. C., Waters, E., \& Wall, S. (1978). Patterns of attachment. Hillsdale, NJ: Erlbaum.

[7] Ainsworth, M. D. S, (1989), Attachment beyond infancy. American psychologist, 44(4), 709-716

[8] Schore, A. N., (2001) Effects of a secure attachment relationship on right brain development, affect regulation and infant mental health. Infant Mental Health Journal, 22(1-2), 7-66.

[9] Robert, G.M., William, J.L., Robert, P.N., Jonathan, J.H., \& David, W. T. (2006). The relationship of attachment insecurity to subjective stress and autonomic function during standardized acute stress in healthy adults. Journal of Psychosomatic Research, 60(3), 283-290. 
[10]Wang, S., Bartolome, J. V., \& Schanberg, S. M. (1996) Neonatal deprivation of maternal touch may suppress ornithine decarboxylase via downregulation of the proto-oncogenes c-myc and max. The Journal of Neuroscience, 16, 836-842.

[11]L. Alan Sroufe (2005) Attachment and development: A prospective, longitudinal study from birth to adulthood, Attachment \& Human Development, 7:4, 349-367,

[12]Joan Stevenson-Hinde (2007) Attachment theory and John Bowlby: Some reflections, Attachment \& Human Development, 9:4, 337-342,

[13]Isabella, R.A.(1993). Origins of attachment: Maternal interactive behavior across the first year. Child Development, 64, 605-621.

[14]Belsky, J., Rovine, M. \& Taylor, D.G. (1984). The Pennsylvania Infant and Family Development Project, III: The Origins of individual differences in infant-mother attachment: Maternal and infant contributions. Child Development, 55, 718-728. (1, 8)

[15]De Wolff, M. S., \& Van Ijzendoorn, M.H. (1997) Sensitivity and attachment: A meta-analysis on parental antecedents of infant attachment. Child Development, 68(4). 571-591

[16]Kagan, J., \&Snidman, N. (1991). Temperamental factors in human development. American Psychologist, 46(8), 856-862

[17]Calkings S.D., Fox N.A., The Relations among Infant Temperament, Security of Attachment, and Behavioral Inhibition at Twenty-Four Months, Child development, 1992.63, 1456-1472

[18]Fox.N.A. Kimmerly.N.L., Schafer.W.D., Erratum: attachment to motherlattachment to father: a meta-analysis, Child Development,1991,62(1):210

[19]Steele, H\& Perez, A\& Segal, F\& Steele, M (2016). Maternal adult attachment interview collected during pregnancy predicts reflective functioning in AAIs from their first-born children 17 years later. International Journal of Developmental Science, 10, 113-120.

[20]Barbaro\& Boutwell\& Barnes\& Shackelford,(2016) Rethinking the Transmission Gap: What Behavioral Genetics and Evolutionary Psychology Mean for Attachment Theory: A Comment on Verhage et al., Psychological Bulletin 2017, Vol. 143, No.1,107-113

[21]Belsky, (1984) Belsky, J. The determinants of parenting: a process model. Child Development, 55(1), 83-96, 1984

[22]Beatrice Beebe , Joseph Jaffe , Sara Markese , Karen Buck , Henian Chen ,Patricia Cohen , Lorraine Bahrick , Howard Andrews \& Stanley Feldstein (2010) The origins of 12-month attachment: A microanalysis of 4-month mother-infant interaction, Attachment \& Human Development, 12:1-2, 3-141,

[23] Verhage, M. L., Schuengel, C., Madigan, S., Fearon, R. M. P., Oosterman, M., Cassibba, R., van IJzendoorn, M. H. (2016). Narrowing the transmission gap: A synthesis of three decades of research on intergenerational transmission of attachment. Psychological Bulletin, 142, 337-366.

[24]Van Bakel, H.J.A., Riksen-Walraven, J. M., (2002). Parenting and development of one-year-olds: links with parental, contextual, and child characteristics. Child Development, 73(1), 256-273.

[25] Arietta Slade (2005) Parental reflective functioning: An introduction, Attachment\& Human Development, 7:3, 269-281.

[26] Verhage, M.L., Schuengel, C., Madigan. S., Fearon. R. M. P., Oosterman, M., Cassibba, R., Bakermans-Kranenburg. M. J. B., \& van Uzendoorn. M.H., (2016) Narrowing the Transmission Gap: A Synthesis of Three Decades of Research on Intergenerational Transmission of Attachment. Psychological Bulletin, 142(4), 337-366 
[27]Kristen Kelly, Arietta Slade \& John F. Grienenberger. (2005) Maternal reflective functioning, mother-infant affective communication, and infant attachment: Exploring the link between mental states and observed caregiving behavior in the intergenerational transmission of attachment, Attachment \& Human Development, 7:3, 299-311,

[28] Swingler. M. M., Perry N.B., Calkins. S. D\& Bell. M.A., (2017) Maternal behavior predicts infant neurophysiological and Behavioral attention process in the first year. Developmental Psychology. 53(1), 12-27

[29]Howard Steele, Alejandra Perez, Francesca Segal\& Miriam Steele, (2016), Maternal Adult Attachment Interview (AAI) Collected During Pregnancy Predicts Reflective Functioning in AAIs from their First-Born Children 17 Years Later. International Journal of Developmental Science, 10, 113-120

[30]Nicolas Berthelot, Karin Ensink, Odette Bernazzani, Lina Normandin, Patrick Luyten\& Peter Fonagy, (2015), Intergenerational transmission of attachment in abused and neglected mothers: the role of trauma-specific reflective functioning. Infant Mental Health Journal, 36(2), 200-212

[31]Kazuko Y. Behrens, John D. Haltigan \& Naomi I. Gribneau Bahm (2016) Infant attachment, adult attachment, and maternal sensitivity: revisiting the intergenerational transmission gap, Attachment \& Human Development, 18:4, 337-353,

[32]W. Roger Mills-Koonce, Jean-Louis Garie'py, Cathi Propper, Kelly Sutton, Susan Calkins, Ginger Moore, Martha Cox, (2017), Infant and parent factors associated with early maternal sensitivity: a caregiver-attachment systems approach, Infant Behavior\& Development, 30, 114-126

[33]K. Lee Rady, Glenn I. Roisman, Cathryn Booth-LaForce, (2015), Brief report: genetic moderation of stability in attachment security from childhood to age 18 years: a replication study. Developmental Psychology, 51(11), 1645-1649

[34] Allan N. Schore, (2001), Effects of a secure attachment relationship on right brain development, affect regulation, and infant mental health. Infant Mental Health Hournal, 22(1-2), 7-66

[35]Luyten, P., Fonagy, P., Lowyck, B., \&Vermote, R. (2012).Theassessment of mentalization. In A. Bateman \& P. Fonagy (Eds.), Mentalizing in clinical health practice. Washington, DC: American Psychiatric Association

[36]Fonagy, P., Gergely, G., Jutist, E., \& Target, M. (2002). Affect regulation, mentalization and the development of the self. New York. NY. Other books.

[37]Fonagy, P., \& Luyten, P. (2009). A developmental, mentalization-based approach to the understanding and treatment of borderline personality disorder. Development \& Psychopathology, 21, 1355-1381

[38]Wismer Fries, A.B., Ziegler, T.E., Kurian, J.R., Jacories, S. \& Pollak, S.D. (2005) Early experience in humans is associated with changes in neuropeptides critical for regulating social behavior. Proceedings of the National Academy of Science of the United States of America, 102:17237-17240.

[39]Schore, A. N. (1994) Affect regulation and the origin of the self. Mahwah, NJ: Lawrence Erlbaum Association, Inc.

[40] Schore, A.N. (2005) Attachment, affect regulation, and the developing right brain: Linking developmental neuroscience to pediatrics. Pediatrics in Review, 26:204-211.

[41]Hosak, L. (2007) Role of the COMT gene Val58Met polymorphism in mental disorders: A review. European Psychiatry, 20: 1-6.

[42]Luther, S.S., Cicchetti, D. \& Becker, B. (2000) The construct of resilience: A critical evalution and guidelines for future work. Child Development, 71: 543-562. 
[43]Reiss, D. \& Leve, L.D. (2007) Genetic expression outside the skin: Clues to mechanisms of genotype * environment interaction. Developmental Psychopathology, 19(4): 1005-1027.

[44] Sullivan, R.M., \& Durfresne, M.M. (2006) Mesocortical dopamine and HPA axis regulation: Role of laterality and early environment. Brain Research, 1076: 49-59. 